\title{
Texture Development, Microstructure Evolution, and Crystallization of Chemically Derived PZT Thin Films
}

San-Yuan Chen

Institute of Materials Science and Engineering, National Chiao-Tung University, Hsinchu 300, Taiwan, Republic of China

I-Wei Chen*

Department of Materials Science and Engineering, The University of Michigan, Ann Arbor, Michigan 48109

Two solution-based methods, metallo-organic decomposition and sol-gel processes, were used to study the effects of precursor solution type on the microstructure evolution and texture development of oriented PZT films. Microstructure development and perovskite content are strongly dependent on the heating rate. Fast heating rate forms a dense fine-grained microstructure with (111) orientation. Intermediate-temperature pyrolysis followed by a fast heating rate forms clustered or island structures of submicrometer grains with (100) orientation. Intermediatetemperature pyrolysis followed by a very slow heating rate forms larger spherical rosettes with random orientations. $\mathrm{Pt}_{5-7} \mathbf{P b}$ is a (111) textured transient intermetallic phase that nucleates PZT(111) texture. PbO is a (001) textured layer compound that nucleates PZT(100) texture. The texture selection of PZT films is independent of precursor systems but sensitive to the film thickness especially when sol-gel precursors and oxidizing atmosphere are used. Correlation and comparison of oriented sol-gel and MOD PZT films with electrical properties are also made.

\section{Introduction}

A WIDE variety of preparation techniques have been employed to produce $\mathrm{Pb}\left(\mathrm{Zr}_{1-x} \mathrm{Ti}_{x}\right) \mathrm{O}_{3}$ (PZT) thin films. Among those methods, the solution-based methods to fabricate ferroelectric thin films offer numerous advantages, including low processing temperature, excellent compositional control, uniform homogeneity, ease of fabrication over large areas, and low cost. Films prepared by such methods have displayed ferroelectric properties comparable to those of bulk ceramics. Two solution-based methods are of particular interest. First, sol-gel processes generally use metal alkoxide precursors which are often water sensitive and seek to maintain close control over hydrolysis and condensation reactions. Polymeric mixed metal alkoxide species can be formed which then serve as molecular building blocks for the subsequent development of crystalline structures. ${ }^{1,2}$ Budd et al. ${ }^{1}$ have used this process with lead acetate, titanium, and zirconium alkoxide precursors to prepare PZT films. In contrast to sol-gel approaches, metallo-organic decomposition (MOD) processes typically use metal carboxylate precursors with larger carbon chains such as 2-ethylhexanoate ${ }^{3}$ and neodecanoate ligands. ${ }^{4}$ The method is

A. H. Carim—contributing editor

Manuscript No. 191446. Received October 18, 1996; approved March 31, 1997. Supported by the National Science Council of the Republic of China through Contract No. NSC86-2621-E-009-020-T.

Member, American Ceramic Society. straightforward and only involves mixing of these waterinsensitive precursors to appropriate stoichiometry. ${ }^{5}$ The cation carboxylates are generally considered unassociated with each other in the mixture because of lack of polymerization. The first PZT film made from the MOD method was prepared by Fukushima et al. ${ }^{3}$ using a solution of lead 2-ethylhexanoate, zirconium acetylacetonate, and titanium tetrabutoxide. Vest and co-workers ${ }^{4}$ developed metal carboxylates, such as lead 2-ethylhexanoate or lead neodecanoate, titanium dimethoxydineodecanoate, and zirconium 2-ethylhexanoate, as precursors. A combined use of sol-gel and MOD precursors is also possible. For example, Mackenzie's group ${ }^{6}$ and Lipeles' group ${ }^{7}$ used lead 2-ethylhexanoate, titanium isopropoxide, and zirconium $n$-propoxide with or without water addition. Recently, Haertling proposed an alternate MOD route in which lead subacetate, lanthanum acetate, zirconium acetate, and titanium acetylacetonate were used. ${ }^{8}$

Highly oriented PZT films (100) and (111) textures have been prepared on $\mathrm{Pt}(111) / \mathrm{Ti} / \mathrm{SiO}_{2} / \mathrm{Si}$ substrates by these chemical methods. ${ }^{9-20}$ The texture formation mechanisms have also been proposed in the literature. ${ }^{12-14,16-19}$ In our previous reports, PZT films of strong (100) and (111) textures or mixed orientations have been successfully developed and elucidated. ${ }^{13,14}$ (100) texture is found to be nucleated by $\mathrm{PbO}$ which tends to form on the Pt substrate with [001] orientation due to its layer structure. (111) texture is found to be nucleated by $\mathrm{Pt}_{5-7} \mathrm{~Pb}$ which tends to form on the Pt substrate with (111) orientation because of lattice matching with $\mathrm{Pt}(111)$. Since both nucleation phases provide good lattice matching with PZT but are transient in nature, texture control is very sensitive to heating schedule, atmosphere, and, in some cases, composition. The above mechanistic understanding was established by using the MOD process, but they should be mostly applicable to other chemical processes such as the sol-gel process. Therefore, in the present work, we have compared the MOD and sol-gel processes in connection with texture control. The systematic difference of these two methods in the carbon content and crystallization temperature also allow us to compare their microstructure development during heat treatment. This has proved helpful to further our understanding of the different mechanisms of $\mathrm{PbO}$ and $\mathrm{Pt}_{5-7} \mathrm{~Pb}$ nucleated textures.

\section{Experimental Procedure}

\section{(1) Precursor Solutions}

Precursor $\mathrm{M}$ (for MOD) is composed of lead 2ethylhexanoate $\left[\mathrm{Pb}\left(\mathrm{C}_{8} \mathrm{H}_{15} \mathrm{O}_{2}\right)_{2}\right]$, zirconium octanoate $\left[\mathrm{Zr}\left(\mathrm{C}_{7} \mathrm{H}_{15} \mathrm{COO}\right)_{4}\right]$, and titanium diethoxydineodecanoate $\left[\mathrm{Ti}\left(\mathrm{OC}_{2} \mathrm{H}_{5}\right)_{2}\left(\mathrm{C}_{9} \mathrm{H}_{19} \mathrm{COO}\right)_{2}\right]$. The general procedures used for fabrication were described in Ref. 14. Precursor S (for sol-gel) was prepared by following the procedure of Budd et al. ${ }^{1}$ Lead acetate trihydrate was first dissolved in methoxyethanol and dehydrated at around $125^{\circ} \mathrm{C}$. After the dehydrated solution was 
cooled to around $90^{\circ} \mathrm{C}$, both titanium ethoxide and zirconium $n$-propoxide were added into the lead solution which was then refluxed at $125^{\circ} \mathrm{C}$ to promote complexion. Subsequently, the solution was vacuum distilled at around $120^{\circ} \mathrm{C}$ to remove the byproducts (esters). Before film deposition, the solution was partially hydrolyzed with $\mathrm{H}_{2} \mathrm{O} / \mathrm{HNO}_{3}$ /methoxyethanol (1.5:0.3: 1.0 molar ratio).

\section{(2) Fabrication of Thin Films}

The main composition studied here was $\mathrm{Pb}_{1.1}\left(\mathrm{Zr}_{0.52} \mathrm{Ti}_{0.48}\right) \mathrm{O}_{3}$ unless otherwise noted. Thin films were fabricated on $\mathrm{Pt}(111) /$ $\mathrm{Ti} / \mathrm{SiO}_{2} / \mathrm{Si}$ substrates by spin coating. Three main heating schedules were used in this work to investigate phase crystallization, microstructure evolution, and texture formation. In schedule I, the deposited films were directly inserted into a hot furnace with high temperatures between $550^{\circ}$ and $900^{\circ} \mathrm{C}$ for 1 min to $1 \mathrm{~h}$ without any prepyrolysis. In schedule II, the deposited films were first pyrolyzed at intermediate temperatures ranging from $350^{\circ}$ to $650^{\circ} \mathrm{C}$ for $0.5 \mathrm{~h}$ and then directly heated to $700^{\circ} \mathrm{C}$ for $0.5 \mathrm{~h}$ to crystallization. In schedule III, the films were pyrolyzed at $400^{\circ} \mathrm{C}$ for $0.5 \mathrm{~h}$ and then heated to 500 $800^{\circ} \mathrm{C}$ with various heating rates from $1^{\circ} \mathrm{C} / \mathrm{min}$ to about $250^{\circ} \mathrm{C} / \mathrm{min}$, later referred to as fast heating. A single-coating was used in most of the work unless otherwise noted. For multiple coatings, the films were additionally given an intermediate heat treatment at $300^{\circ} \mathrm{C}$ on a hot plate for 2 min after each coating.

\section{(3) Characterization of Solutions and Thin Films}

TGA and DTA were performed to analyze the thermal decompositions and transformation of precursor solutions. Since drying of solvent has been found unimportant in our previous work for texture, both MOD and sol-gel solutions were thoroughly dried at $150^{\circ} \mathrm{C}$ for $10 \mathrm{~h}$ prior to DTA-TGA. The orientation of the films was determined by the standard 0-20 X-ray diffraction (XRD) method. Furthermore, the integrated intensities of the three peaks (100), (110), and (111) were used to quantify texture. For calibration, these peak intensities were normalized by the corresponding intensities obtained for powdered samples. The relative intensity is defined as in our previous work as

$$
\left(I / I^{*}\right) /\left[\left(I / I^{*}\right)_{100}+\left(I / I^{*}\right)_{110}+\left(I / I^{*}\right)_{111}\right]
$$

where $I$ represents the integrated intensity of a particular reflection $(100,110,111)$ for the films, and $I^{*}$ represents its counterpart for the powdered sample. The microstructure and thickness of the films were examined using scanning electron microscopy (SEM). The details of measurement of electrical properties will be described in our other report. ${ }^{21}$

\section{Results and Discussion}

\section{(1) Thermal Decomposition and Phase Transformation of Precursor Solutions}

Figure 1 shows the DTA-TGA analyses for precursors $\mathrm{M}$ and $\mathrm{S}$ at a heating rate of $10^{\circ} \mathrm{C} / \mathrm{min}$. The thermal behavior of MOD solution (M) has already been described in detail in Ref. 14. The weight loss of precursor $\mathrm{M}$ between $150^{\circ}$ and $375^{\circ} \mathrm{C}$ corresponds to the removal and decomposition of organic groups such as octanoate, 2-ethylhexanoate, and neodecanoate; at higher temperature no further weight loss can be detected. The two exothermic peaks at $320^{\circ}$ and $370^{\circ} \mathrm{C}$ result from the $\mathrm{PbO}$ phase formation (detected by XRD) and decomposition of organic compounds. Two other broad peaks (confirmed by XRD) without weight loss are for the pyrochlore phase formation starting around $390^{\circ} \mathrm{C}$ and perovskite formation beginning about $490^{\circ} \mathrm{C}$.

For sol-gel precursor (S), the first exothermic peak around $330^{\circ} \mathrm{C}$ with a large weight loss corresponds to the decomposition of most of the organic substance. The second exothermic peak at $425^{\circ} \mathrm{C}$ is accompanied by a smaller weight loss at the
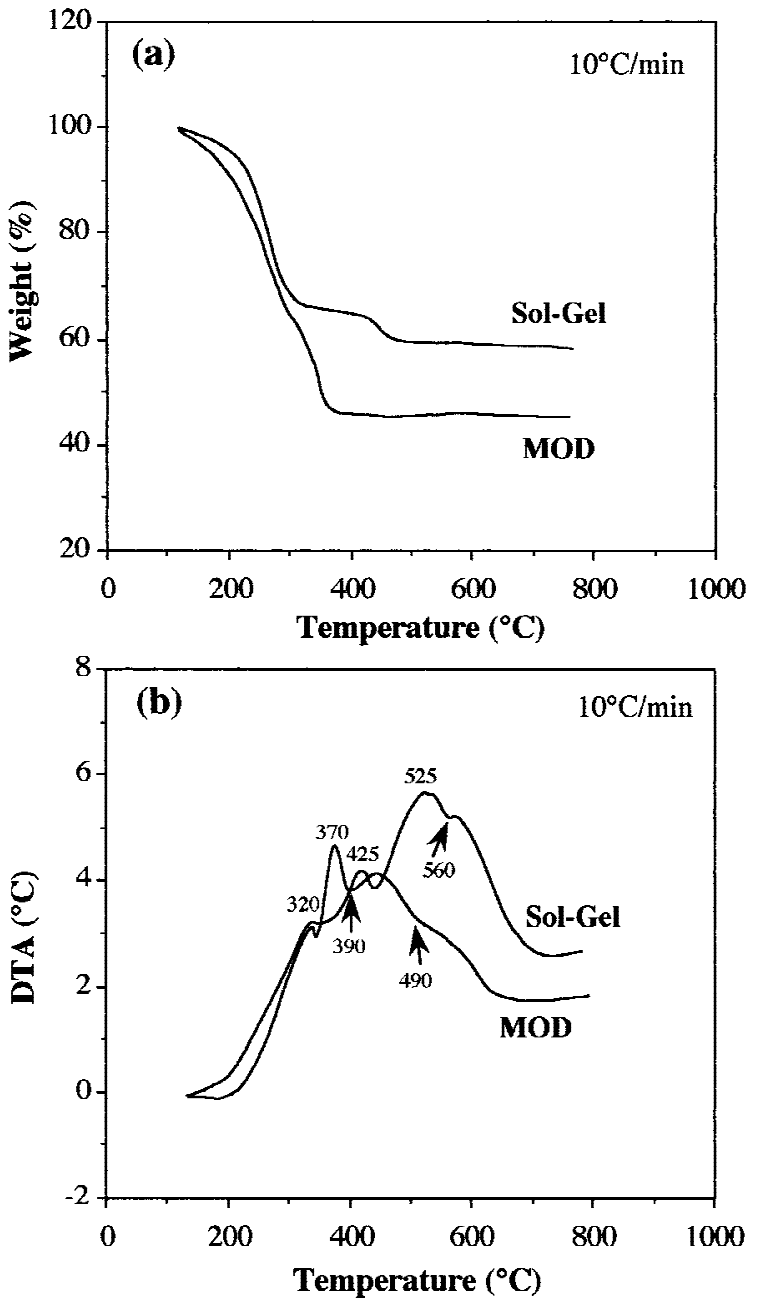

Fig. 1. (a) TGA and (b) DTA curves of MOD and sol-gel PZT precursors.

temperature range of $400-450^{\circ} \mathrm{C}$. According to the explanation of Lakeman et al. ${ }^{22}$ from FTIR analysis, only terminal alkoxy ligands are easily removed at low temperatures, leaving stronger bridging ligands intact. The required temperature for their decomposition increases with the amount of water addition because of the larger number of bridging ligands formed. This is thought to correspond to the second exothermic peak noted above. Lastly, according to XRD analysis, the third broad exothermic peak between $430^{\circ}$ and $550^{\circ} \mathrm{C}$ without any additional weight loss is probably related to the formation of pyrochlore phase, and the fourth exothermic peak, starting around 550 $570^{\circ} \mathrm{C}$, but again without weight loss, corresponds to perovskite formation.

A comparison of the thermograms of MOD and sol-gel solutions leads to the following conclusions: (i) The total weight loss of MOD solution is higher than that of sol-gel solution, reflecting a higher carbon content of the former. (ii) The phase transformation temperatures of amophorous-to-pyrochlore and pyrochlore-to-perovskite are both higher in sol-gel solution than in MOD solution, reflecting stronger chemical bonding of the former. These differences will be shown to influence the texture development and microstructure evolution of PZT films.

\section{(2) Texture Development}

Our previous results, using precursor $\mathrm{M}$, have demonstrated that different textures can be obtained by controlling heating schedules. ${ }^{14}$ For example, if the film is directly heated to $700^{\circ} \mathrm{C}$ without pyrolysis (schedule I), (111) texture dominates 
(Fig. 2(a)). On the other hand, if the film is first held at $400^{\circ} \mathrm{C}$ for $0.5 \mathrm{~h}$, cooled, then directly heated to $700^{\circ} \mathrm{C}$ and held for 0.5 h (schedule II), a very strong (100) texture is obtained (Fig. 2(b)). Lastly, an apparently random texture almost indistinguishable from that of the powdered sample (Fig. 2(c)) can be obtained by very slow heating $\left(1^{\circ} \mathrm{C} / \mathrm{min}\right)$ from room temperature to $700^{\circ} \mathrm{C}$.

To compare precursors $\mathrm{M}$ and $\mathrm{S}$ for texture development, heating schedule I was first used. Films with single coating were directly inserted into a hot furnace at $700^{\circ} \mathrm{C}$ for $0.5 \mathrm{~h}$. We found that although a highly oriented (111) texture was always obtained for MOD films, sol-gel films had a mixture of (100) and (111) textures. However, when thicker films with multiple coatings were used, even sol-gel films developed a highly oriented (111) texture. The above results can be understood by referring to the formation of intermetallic phase $\mathrm{Pt}_{5-7} \mathrm{~Pb}(111)$ which is epitaxial with both $\mathrm{Pt}(111)$ and $\mathrm{PZT}(111)$. As we illustrated in our previous study, ${ }^{13}$ when the films were fired in a reducing atmosphere or directly heated at high temperature for a very short time (ex. $600^{\circ} \mathrm{C}$ for $1-2 \mathrm{~min}$ ), a redox reaction at the buried PZT/Pt interface, where a low oxygen partial pressure temporarily prevailed during fast heating, was formed because of insufficient oxygen for pyrolyzing organics. This caused the reduction to $\mathrm{Pb}^{2+}$ into metallic $\mathrm{Pb}$, which in turn formed $\mathrm{Pt}_{5-7} \mathrm{~Pb}$ on the substrate interface. $\mathrm{PZT}(111)$ could then be nucleated on $\mathrm{Pt}_{5-7} \mathrm{~Pb}$ before its reoxidation by surface influx of $\mathrm{O}_{2}$ into ceramics. Since the organic content of sol-gel precursor is lower than MOD precursor, the oxygen partial pressure was probably not low enough in thinner sol-gel films to reduce $\mathrm{Pb}^{2+}$ or to maintain $\mathrm{Pt}_{5-7} \mathrm{~Pb}$ during fast heating. Thus, (111) texture could not be obtained in sol-gel films. This condition could be remedied by using a thicker film, or by using a
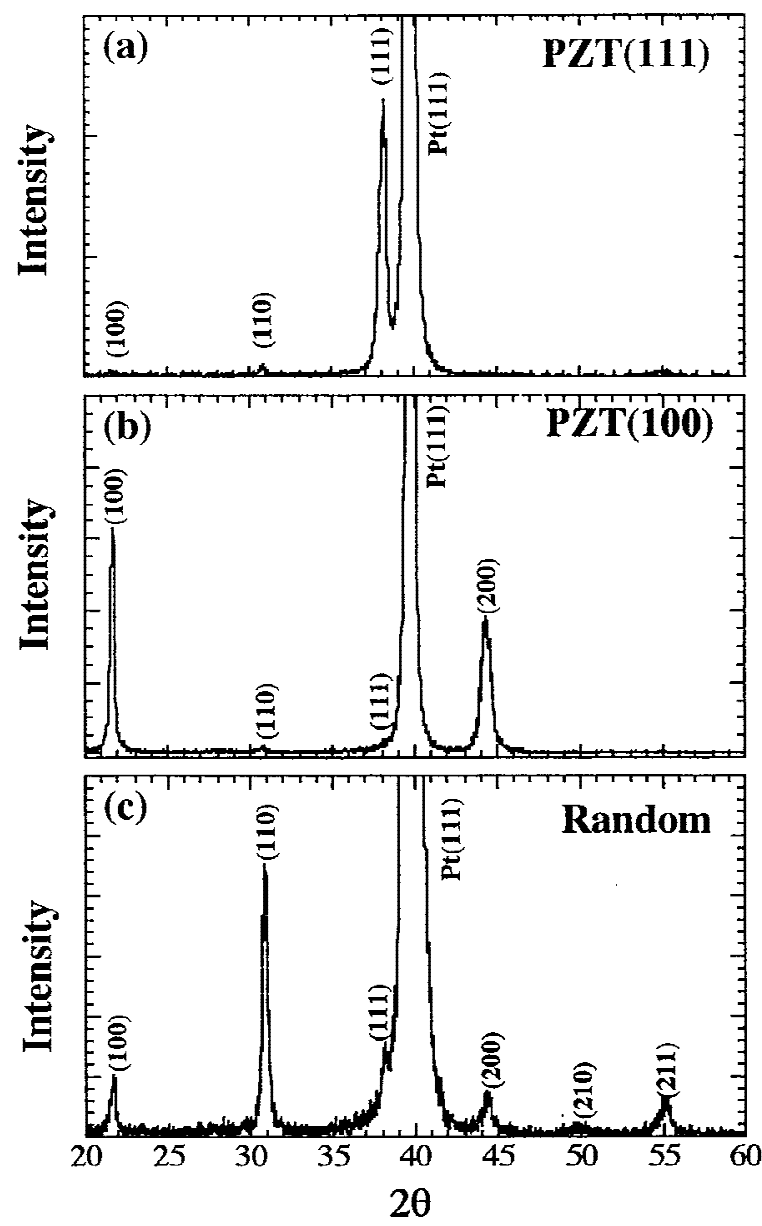

Fig. 2. XRD patterns of PZT films with (a) (111) texture, (b) (100) texture, and (c) random texture. less oxidizing atmosphere. As shown in Fig. 3, both are effective for promoting (111) texture in the sol-gel films, in agreement with our expectation. In particular, the thickness effect is consistent with our interpretation that the later intake of oxygen is from the surface by inward diffusion, and is the cause for destruction of the transient $\mathrm{Pt}_{5-7} \mathrm{~Pb}$ phase and the termination of the (111) seeding process.

We have used different pyrolysis temperatures before heating the films to $700^{\circ} \mathrm{C}$ for $0.5 \mathrm{~h}$ (schedule II) to compare the behavior of MOD and sol-gel films. The results of this study on texture are shown in Fig. 4. (100) texture was found for both films using intermediate pyrolysis temperatures. However, there are apparently different behaviors between these two precursors at very high and very low pyrolysis temperatures. At the very low temperature, $350^{\circ} \mathrm{C}$, pyrolysis was incomplete. Thus, further pyrolysis and formation of $\mathrm{Pt}_{5-7} \mathrm{~Pb}$ could still occur during subsequent heating to $700^{\circ} \mathrm{C}$. This reverts the heat treatment to schedule I, so that, according to Fig. 3, MOD films formed (111) and not (100) texture. Likewise, a higher pyrolysis temperature between $600^{\circ}$ and $700^{\circ} \mathrm{C}$ was also similar to the heat treatment of schedule I, resulting in the dominance of (111) and not (100) texture for MOD films. (In both cases, sol-gel films obtained about $50 \%$ of (111) texture according to Fig. 3).

For the case of intermediate pyrolysis temperatures, we have illustrated in Ref. 13 that (100) texture was formed on a $(\mathrm{PbO})_{001}$ buffer layer at the PZT/Pt interface. This is because the $\mathrm{PbO}[001]$ plane matches well in lattice arrangement with that of PZT[100] $\left(a_{0}=3.9723 \AA\right.$ for O-sublattice in $\mathrm{PbO}$ versus $a_{0}=4.05 \AA$ for $\mathrm{O}$ or cation sublattices in PZT). The origin of $\mathrm{PbO}[001]$ texture is attributed to the layerlike structure of this compound which contains $\mathrm{Pb}$ with lone-pair electrons, and the $\mathrm{PbO}[001]$ texture is itself favored on the substrate because of its layerlike structure. Since, under oxidizing conditions, $\mathrm{PbO}$ eventually forms at intermediate pyrolysis temperatures PZT(100) can be seeded and then grown onto $(\mathrm{PbO})_{001}$ during later heating to high temperatures.

To demonstrate this effect, we prepared samples with a thin $(\sim 0.05 \mu \mathrm{m})$ coating of lead 2-ethylhexanoate, then pyrolyzed them at $400^{\circ} \mathrm{C}$ for $0.5 \mathrm{~h}$ to obtain $\mathrm{PbO}[001]$, then recoated them with the metallorganic solution corresponding to PZT stoichiometry, and finally pyrolyzed them again using the two heating schedules (I and II). With the PbO buffer, a strong PZT(100) peak is obtained independent of heating schedules used. The formation condition is not stringent and $\mathrm{PbO}$ tends to be the first phase formed on the substrate at lower temperature, leading to subsequent PZT(100) selection. Furthermore, pyrochlore

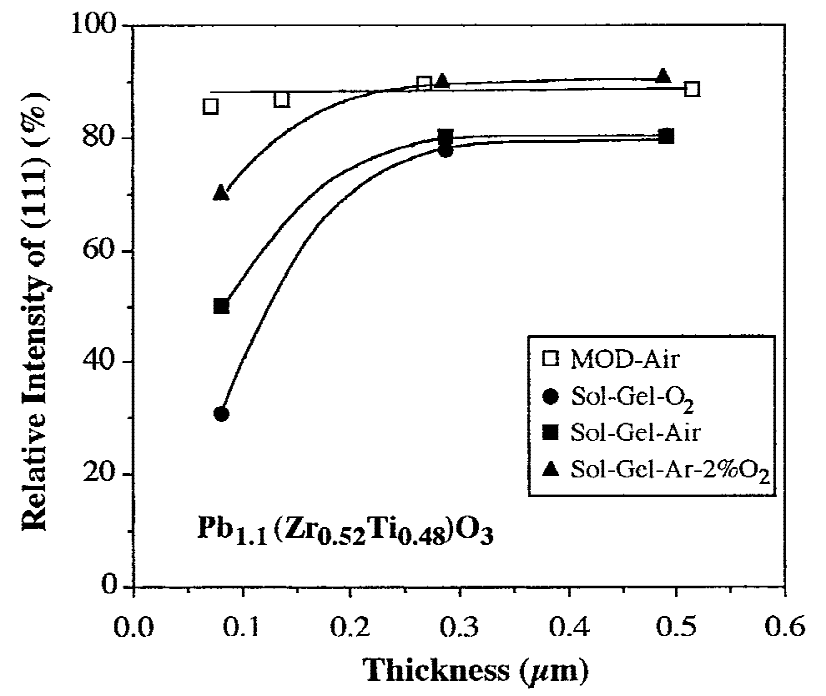

Fig. 3. Effect of film thickness on relative intensity of (111) for both MOD and sol-gel PZT films. 


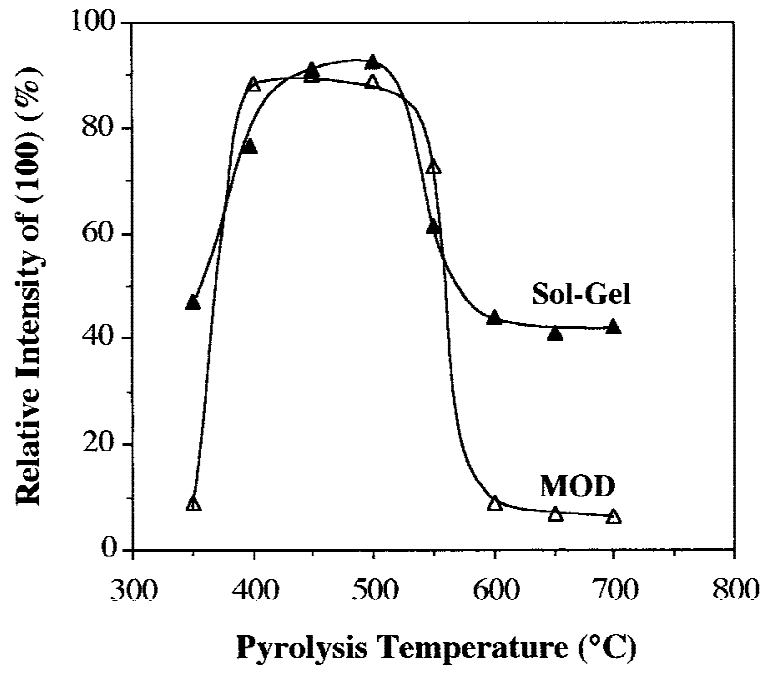

Fig. 4. Effect of pyrolysis temperature on relative intensity of (111) for both MOD and sol-gel PZT films.

forms at a lower temperature than perovskite but does not have a special texture and probably does not originate from the substrate interface. It has a lattice structure which does not provide any special plane for good matching with PZT(100). It is also rather ionic in nature and has little tendency to grow in a layerlike pattern. Therefore, it has no influence on the selection of PZT texture and will decompose at higher temperature to reform perovskite PZT.

The above comparison indicates that the conditions for (111) and (100) texture control are essentially the same for both MOD and sol-gel films, especially if thicker films are used and borderline conditions are avoided. To investigate the condition for obtaining mixed or essentially random textures, schedule III (pyrolysis at $400^{\circ} \mathrm{C}$ for $0.5 \mathrm{~h}$, followed by heating at different rates to $700^{\circ} \mathrm{C}$, then held for $0.5 \mathrm{~h}$ ) was used. As shown in Fig. 5 , at a heating rate lower than $10^{\circ} \mathrm{C} / \mathrm{min}$, a mixed texture of (100) and (111) could be obtained in MOD films. This was also the case for sol-gel films at a heating rate of $5^{\circ} \mathrm{C} / \mathrm{min}$. At the lowest heating rate of $1^{\circ} \mathrm{C} / \mathrm{min}$, the relative intensities of (110), (100), and (111) reflections in the sol-gel films were essentially the same as powdered samples. Thus, a random texture was formed in this case.

\section{(3) Analysis of Texture Formation}

There has been considerable work on orientation development of PZT thin films on similar substrates (i.e., $\mathrm{Pt}(111) / \mathrm{Ti} /$ $\mathrm{SiO}_{2} / \mathrm{Si}$ ) during heat treatment. ${ }^{9-20}$ For the nucleation of PZT(111) orientation, two major mechanisms have been proposed to date in the literature. The first proposed mechanism is that PZT(111) nucleates via a transient intermetallic phase $\left(\mathrm{Pt}_{3} \mathrm{Ti}^{12}\right.$ or $\left.\mathrm{Pt}_{5-7} \mathrm{~Pb}^{13}\right)$ because of the almost identical (111) lattice parameters of the two phases. The second proposed mechanism is the direct nucleation of PZT seed on Pt due to lattice matching between PZT(111) and Pt(111) at the film/Pt interface. ${ }^{16-18}$ For the case of the (100)-oriented films, most of the literature has reported that the (100) orientation was observed because (100) is an energetically favored growth plane. ${ }^{12,17,18} \mathrm{We}$, however, indeed observed that with $\mathrm{PbO}(001)$ buffer, PZT(100) texture was promoted and PZT(111) texture was suppressed. ${ }^{13}$

If the orientation selection of PZT films is based only on the consideration of lattice matching and minimum surface energy, the texture development of perovskite materials with similar lattice constant to PZT would follow the above-mentioned latter nucleation map [(111) is due to lattice matching between film/Pt and (100) is due to an energetically favored growth plane]. To elucidate the postulation, a series of experiments were designed to study the effect of perovskite structure on
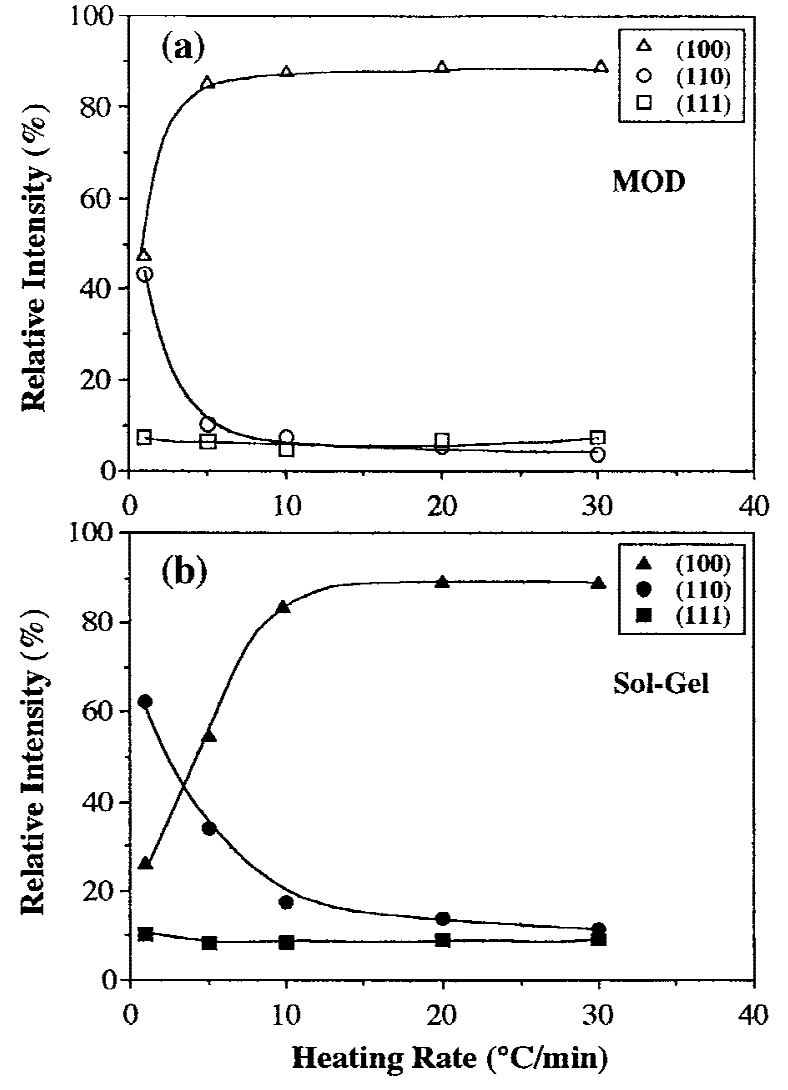

Fig. 5. Normalized relative intensity for three perovskite reflections as a function of heating rate for (a) MOD and (b) sol-gel PZT films.

texture development during thermal processing. It was found that dependence of preferred orientation on heat treatments similar to that of our PZT films was observed for $\mathrm{Pb}\left(\mathrm{Mg}_{1 / 3}, \mathrm{Nb}_{2 / 3}\right) \mathrm{O}_{3}$ film but not for $\mathrm{BaTiO}_{3}$ film. This leads us to strongly believe the importance of both $\mathrm{PbO}$ and $\mathrm{Pb}-\mathrm{Pt}$ intermetallic phases on the texture development in our PZT films.

From the viewpoint of texture development of PZT films on $\mathrm{Pt}(111) / \mathrm{Ti} / \mathrm{SiO}_{2} / \mathrm{Si}$ substrate during thermal processing, pyrolysis temperature and atmosphere control in postpyrolysis treatments have been the critical parameters for controlling the nucleation growth, texture evolution, and final microstructure of the films. ${ }^{14-20}$ As shown in Fig. 3, it was observed that oxidizing atmosphere suppresses (111) texture but promotes (100) texture in the sol-gel films. Our observations were considerably consistent with the report of Brooks et al. ${ }^{17}$ that heat treatments in oxygen favor the (100)-oriented growth. Regarding the effect of pyrolysis temperature on texture development of PZT films, Fig. 4 shows that pyrolysis in the temperature region of $400-550^{\circ} \mathrm{C}$ strongly promotes (100) textured PZT films. In this regard, similar results are also reported by Reaney et al. ${ }^{19}$ and Brooks et al. ${ }^{17,20}$ but contrary to those of Liu and Phule. ${ }^{18}$

Actually, considering the specific case of films prepared by the chemical techniques of MOD and sol-gel, other factors are known to impact on texture evolution such as precursor selection, film synthesis, combustion characteristics of deposited film, and film thickness. ${ }^{19,21,22}$ In our experiments, it was observed that after pyrolysis and annealing at high temperature a single deposited PZT layer, especially for sol-gel films, exhibits somewhat different texture from multiple deposited layers (four layers) with intermediate heat treatment on a hot plate to burn out the organics (thickness effect). The preferred orientation of multiple deposited PZT layers was found to be dependent on the temperature on a hot plate. Furthermore, Aoki and co-workers ${ }^{23}$ used a sol-gel process for the deposition of PZT thin films and noted that thinner films $(t<100 \mathrm{~nm}$ per 
layer) exhibited a strong (100) texture. Therefore, different mechanisms for texture development were proposed in the related literature because precursor solution, combustion conditions, and film thickness used for texture evolution are completely different from one to another. Further investigation based on the same experimental conditions for different precursor solutions is needed to obtain an unequivocal explanation of the formation mechanism for the development of preferred orientation.

\section{(4) Phase Crystallization}

Heating schedule III (pyrolyzed first at $400^{\circ} \mathrm{C}$, then heated at $15^{\circ} \mathrm{C} / \mathrm{min}$ to various temperatures between $500^{\circ}$ and $700^{\circ} \mathrm{C}$ ) was used to study the phase crystallization and microstructure evolution. XRD analyses of MOD films showed a broad peak at 20 around $29^{\circ}$ for the films pyrolyzed at $400^{\circ} \mathrm{C}$ for $0.5 \mathrm{~h}$, indicating the presence of a mixture of amorphous and pyrochlore phases. Above $450^{\circ} \mathrm{C}$, two obvious pyrochlore peaks could be identified, and they became quite prominent especially at $500^{\circ} \mathrm{C}$. Above $520^{\circ} \mathrm{C}$, perovskite peaks appeared in a pyrochlore background. At $550^{\circ} \mathrm{C}$, only perovskite (100) and (200) peaks remained (Fig. 6(a)).

For sol-gel films, XRD indicated that they remained amorphous below $400^{\circ} \mathrm{C}$, amorphous with a very small amount of pyrochlore at $400^{\circ} \mathrm{C}$, and then formed a broad peak at 20 around $29^{\circ}$ corresponding to pyrochlore at $500^{\circ} \mathrm{C}$. At $550^{\circ} \mathrm{C}$, the XRD pattern showed a small (100) peak of perovskite phase coexisting with pyrochlore (Fig. 6(b)). Above $600^{\circ} \mathrm{C}$, perovskite phase dominated without pyrochlore remaining. These results clearly illustrate that the crystallization tempera-
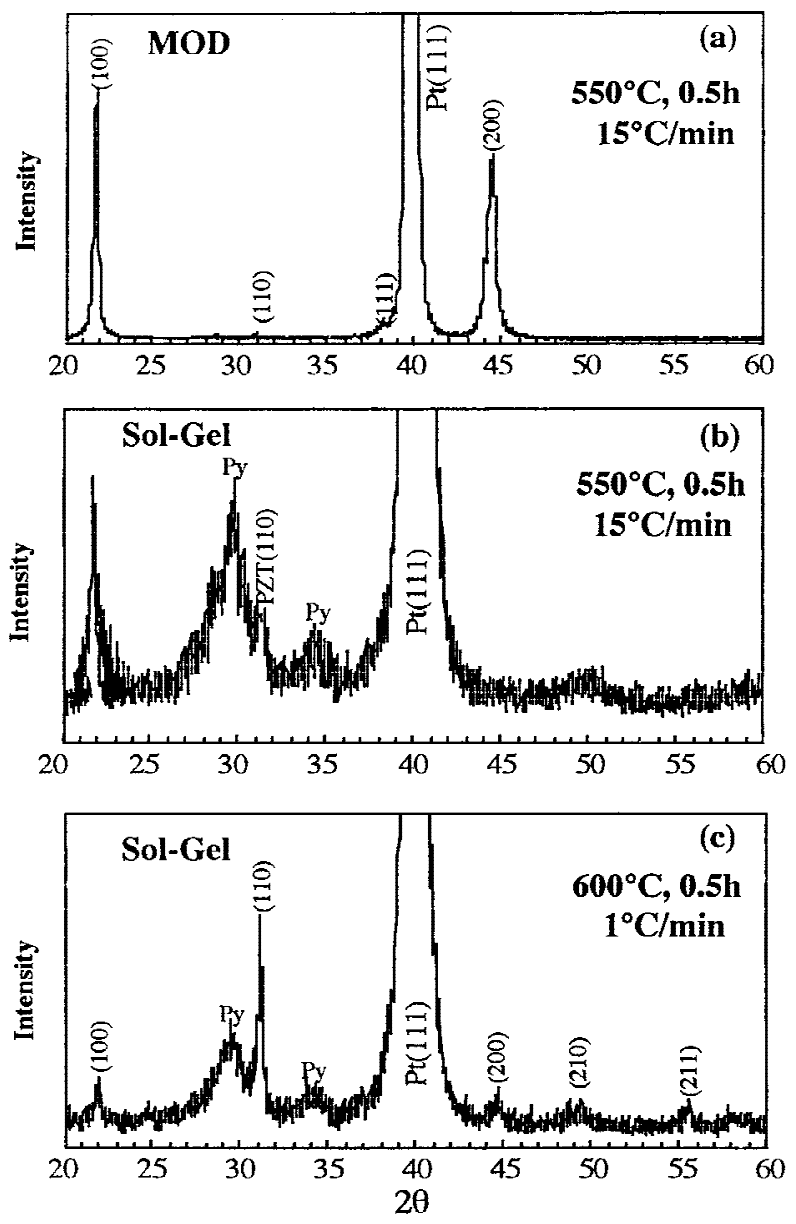

Fig. 6. XRD patterns of three samples first pyrolyzed at $400^{\circ} \mathrm{C}$ for $0.5 \mathrm{~h}$ : (a) MOD film heated to $550^{\circ} \mathrm{C}$ with a heating rate of $15^{\circ} \mathrm{C} / \mathrm{min}$, (b) sol-gel film heated to $550^{\circ} \mathrm{C}$ with a heating rate of $15^{\circ} \mathrm{C} / \mathrm{min}$, (c) sol-gel film heated to $600^{\circ} \mathrm{C}$ with a heating rate of $1^{\circ} \mathrm{C} / \mathrm{min}$. tures of both pyrochlore and perovskite are higher in the solgel films than MOD films.

When a lower heating rate of $1^{\circ} \mathrm{C} / \mathrm{min}$ instead of $15^{\circ} \mathrm{C} / \mathrm{min}$ was used, essentially random texture with a major (110) peak of perovskite was observed above $550^{\circ} \mathrm{C}$ for both MOD and sol-gel processes. However, for sol-gel films, pyrochlore phase was still observed above $600^{\circ} \mathrm{C}$ (Fig. 6(c)) whereas it was absent in MOD films for the same composition of $\mathrm{Pb}_{1.1}\left(\mathrm{Zr}_{0.52} \mathrm{Ti}_{0.48}\right) \mathrm{O}_{3}$. The pyrochlore phase did not disappear even after holding at $700^{\circ} \mathrm{C}$ for $0.5 \mathrm{~h}$ in the sol-gel films.

\section{(5) Microstructure Development}

To elucidate the crystallization and texturing process, SEM micrographs were taken to observe the microstructure evolution between $500^{\circ}$ and $700^{\circ} \mathrm{C}$ for MOD and sol-gel films. Heating schedules with three heating rates ranging from very fast to very slow were used to produce different textures. These results are described below.

(A) (111) Textured Films: Under heating schedule I (directly inserted into a preset temperature without any prepyrolysis), (111) texture is always favored for a thick film. When the film was directly fired to $650^{\circ} \mathrm{C}$ and held for only $2 \mathrm{~min}$, the XRD pattern showed an intermetallic $\mathrm{Pt}_{5-7} \mathrm{~Pb}$ phase but the microstructure was featureless as shown in Fig. 7(a). This is not surprising because the intermetallic phase exists only at the buried interface. Later, with an annealing time of $0.5 \mathrm{~h}$ at $650^{\circ} \mathrm{C}$, a uniform microstructure with fine "grains" was developed for both MOD (Fig. 7(b)) and sol-gel films (Fig. 7(c)). The "grain boundaries" seen in the micrographs are believed to contain some porosity. The grain size of the MOD films was smaller, and the microstructure less uniform than those of the sol-gel films.

According to our previous study, under fast heating conditions, PZT rapidly nucleates from the intermetallic $\mathrm{Pt}_{5-7} \mathrm{~Pb}$ phase, forming (111) texture. The high nucleation rate produces a microstructure with a uniform and small grain size. the dense microstructure of the sol-gel films may be attributed to the lower carbon content in its precursors, resulting in less residual carbon which causes low degassing and porosity formation at higher temperature. (Lipeles et al. ${ }^{24}$ reported that some 2-ethylhexanoate ligands still remained even after pyrolysis at $400^{\circ} \mathrm{C}$.) The larger grain size of the sol-gel films may also reflect the higher crystallization temperature. This effect has been previously seen in our study of the $\mathrm{Zr} / \mathrm{Ti}$ influence in PZT (see Ref. 14), where the difficulty in perovskite formation with $\mathrm{Zr}$ rich composition was found to result in a larger grain or rosette size. ${ }^{25}$

(B) (100) Textured Films: Under heating schedule III, with a heating rate of $15^{\circ} \mathrm{C} / \mathrm{min}$ following $400^{\circ} \mathrm{C}$ pyrolysis, (100) texture is favored. Independent of precursor system, the SEM micrographs of films fired at $500^{\circ} \mathrm{C}$ were featureless even though XRD indicated the presence of pyrochlore. According to the TEM analysis of Tuttle et $a .^{26}$ the featureless matrix consists of interpenetrating nanocrystalline pyrochlore and amorphous phases, both with dimensions on the order of $5 \mathrm{~nm}$. When the temperature was increased to $550^{\circ} \mathrm{C}$, the microstructure of MOD films consisted of a clustered structure with many small-sized grains (Fig. 8(a)), and XRD revealed that it had highly (100) texture. At higher temperatures, the cluster-grain structure became well delineated as seen in Figs. 8(b) and (c). Meanwhile, the pore number increased with temperature, indicating additional degassing due to $\mathrm{PbO}$ evaporation and/or the release of residual organics.

For sol-gel films, the perovskite crystals began to nucleate out of the pyrochlore matrix at $550^{\circ} \mathrm{C}$ according to $\mathrm{XRD}$. These crystallites were in isolated islands (Fig. 9(a)), not clustered with each other as in MOD films (Fig. 8(a)). The island structure was basically composed of submicrometer-sized grains which became more distinguishable at increasing temperatures above $600^{\circ} \mathrm{C}$ (Fig. 9(b)). Meanwhile, more islands formed and they began to impinge on each other. At $650^{\circ} \mathrm{C}$, a dense microstructure consisting of mostly perovskite (100) grains with 

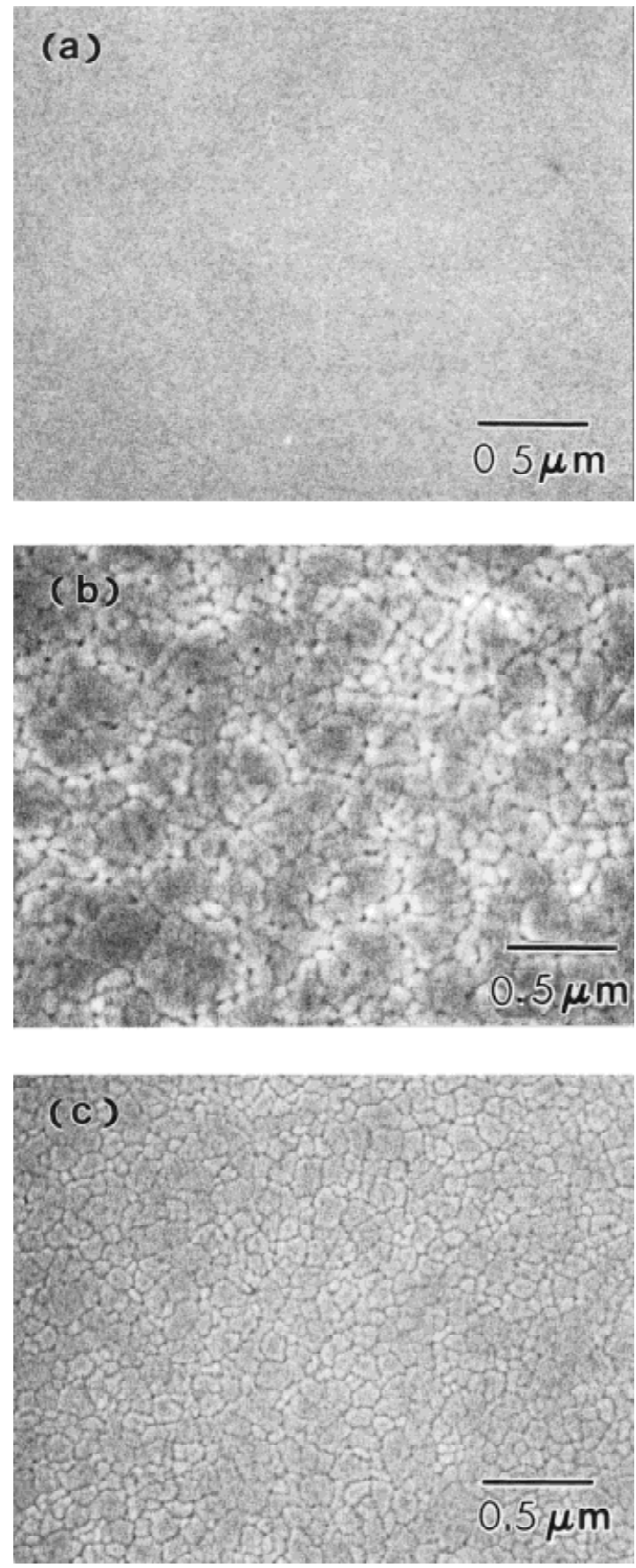

Fig. 7. SEM micrographs of PZT films fast heated at $650^{\circ} \mathrm{C}$ for (a) $2 \mathrm{~min}$ for MOD, (b) $0.5 \mathrm{~h}$ for MOD, and (c) $0.5 \mathrm{~h}$ for sol-gel.

some residual pyrochlore was formed (Fig. 9(c)). (If $15 \mathrm{~mol} \%$ excess of $\mathrm{Pb}$ was incorporated into the sol-gel precursor, an essentially single perovskite phase was obtained for sol-gel films.) Thus, apparently, under the heating schedule appropriate for (100) texture selection, MOD films crystallized at a lower temperature and the reaction into perovskite was more complete than sol-gel films.

The above observations can be understood from the connection between $(\mathrm{PbO})_{001}$ and PZT (100) texture. According to the results of Ref. 13, $(\mathrm{PbO})_{001}$ formation as a buffer layer is favored at low temperature, and it exists in both tetragonal and orthorhombic forms with very similar textures. At high temperatures, however, $\mathrm{PbO}$ evaporation is severe, causing the loss of the buffer layer. Since sol-gel precursors crystallize at higher temperatures, as evident from the less developed island microstructure in sol-gel films at $550^{\circ} \mathrm{C}$ compared to the clus-
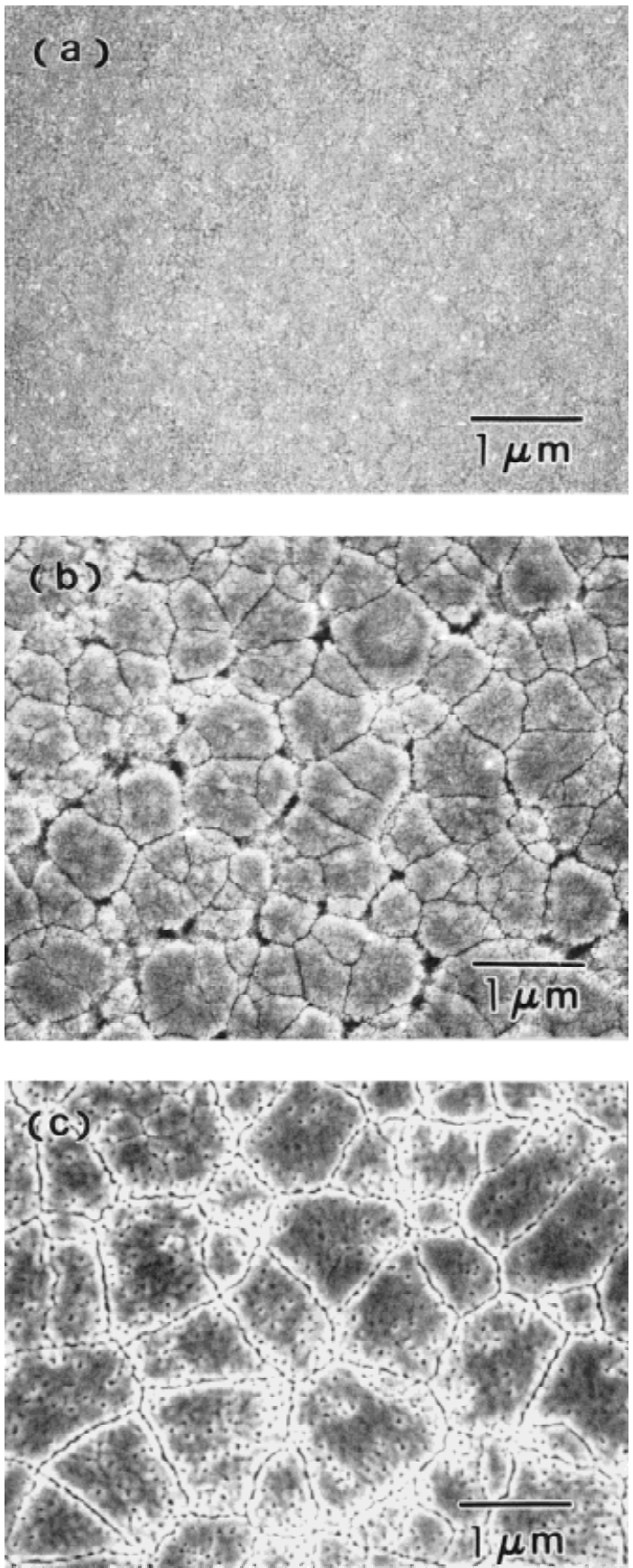

Fig. 8. SEM micrographs of MOD films first pyrolyzed at $400^{\circ} \mathrm{C}$ for $0.5 \mathrm{~h}$ and then heated at (a) $550^{\circ}$, (b) $600^{\circ}$, and (c) $700^{\circ} \mathrm{C}$ for $0.5 \mathrm{~h}$ with a heating rate of $15^{\circ} \mathrm{C} / \mathrm{min}$.

tered structure at the same temperature in MOD films, the remaining untransformed areas are subject to $\mathrm{PbO}$ loss resulting in both destruction of $(\mathrm{PbO})_{001}$ (hence reduced area for heterogeneous nucleation of perovskite) and pyrochlore stabilization. This gives rise to a less uniform microstructure with a larger grain size and some residual pyrochlore.

(C) Random Textured Films: At a heating rate of $1^{\circ} \mathrm{C} /$ min, an essentially random texture could be obtained in both MOD and sol-gel films. The MOD films fired above $550^{\circ} \mathrm{C}$ were composed of a featureless pyrochlore matrix and rosettelike clusters (about 1-3 $\mu \mathrm{m}$ in diameter) which seemed to be roughly spherical/circular aggregates of polycrystallites with fuzzy outer boundaries (Figs. 10(a) and (b)). According to the study of Myers and Chapin, ${ }^{26}$ the rosettes (which have some resemblance to spherulites in high polymers and many monomeric compounds ${ }^{28}$ ) are nucleated from an equiaxed seed 

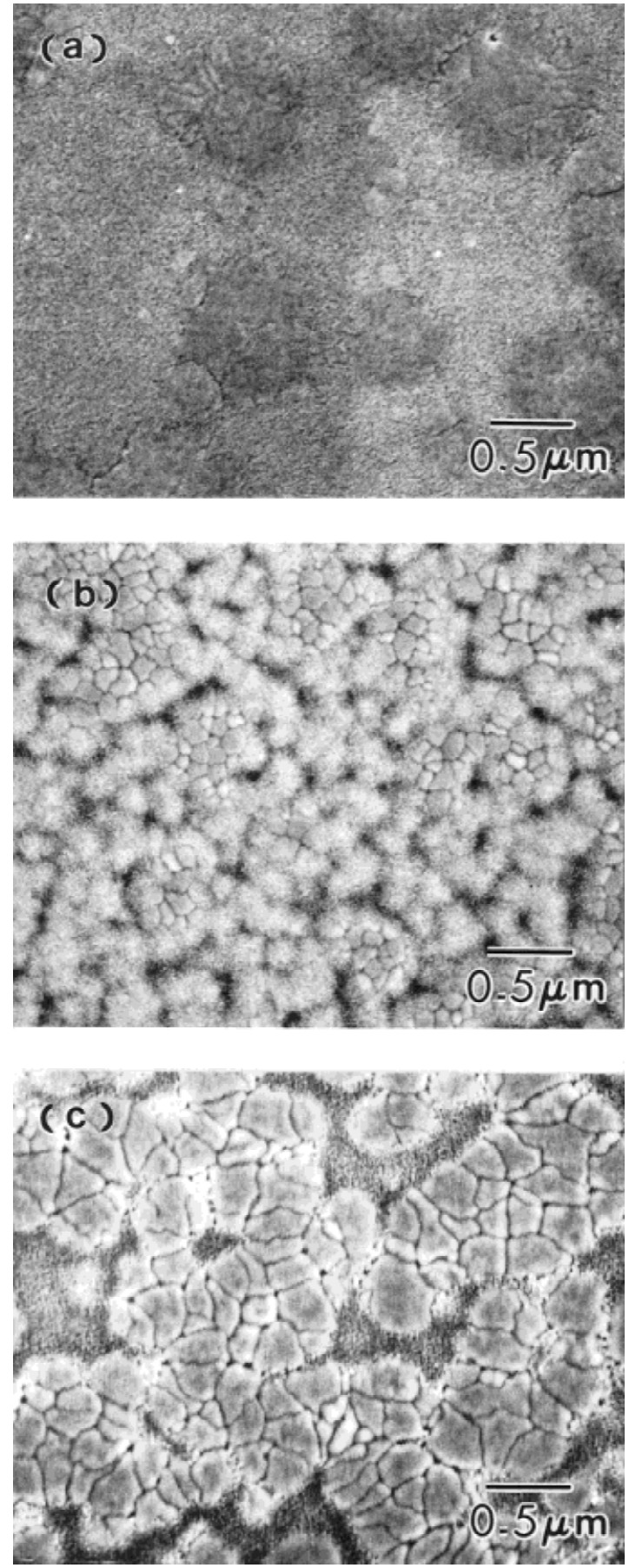

Fig. 9. SEM micrographs of sol-gel films first pyrolyzed at $400^{\circ} \mathrm{C}$ for $0.5 \mathrm{~h}$ and then heated at (a) $550^{\circ}$, (b) $600^{\circ}$, and (c) $700^{\circ} \mathrm{C}$ for 0.5 $\mathrm{h}$ with a heating rate of $15^{\circ} \mathrm{C} / \mathrm{min}$.

grain from which emanate radially lamellae of perovskite PZT with different crystallographic orientations. Therefore, no preferred orientation is expected, in accordance with our XRD results.

For sol-gel films, the two-phase microstructure with a featureless pyrochlore matrix and spherical (circular) perovskite grains (about 2-7 $\mu \mathrm{m}$ ) was also observed. The spherical structures (Fig. 11(a)), however, had very sharp boundaries. In some cases, a center nucleus could be identified (Fig. 11(b)) and the growth could be seen as distinctly radial in direction. (When a primary nucleus is not seen, it may still very well exist but could be buried beneath the surface). Using electron diffraction in TEM, Carim et al. ${ }^{29}$ reported that the spherical rosettes of this kind were single crystals with numerous pores on the
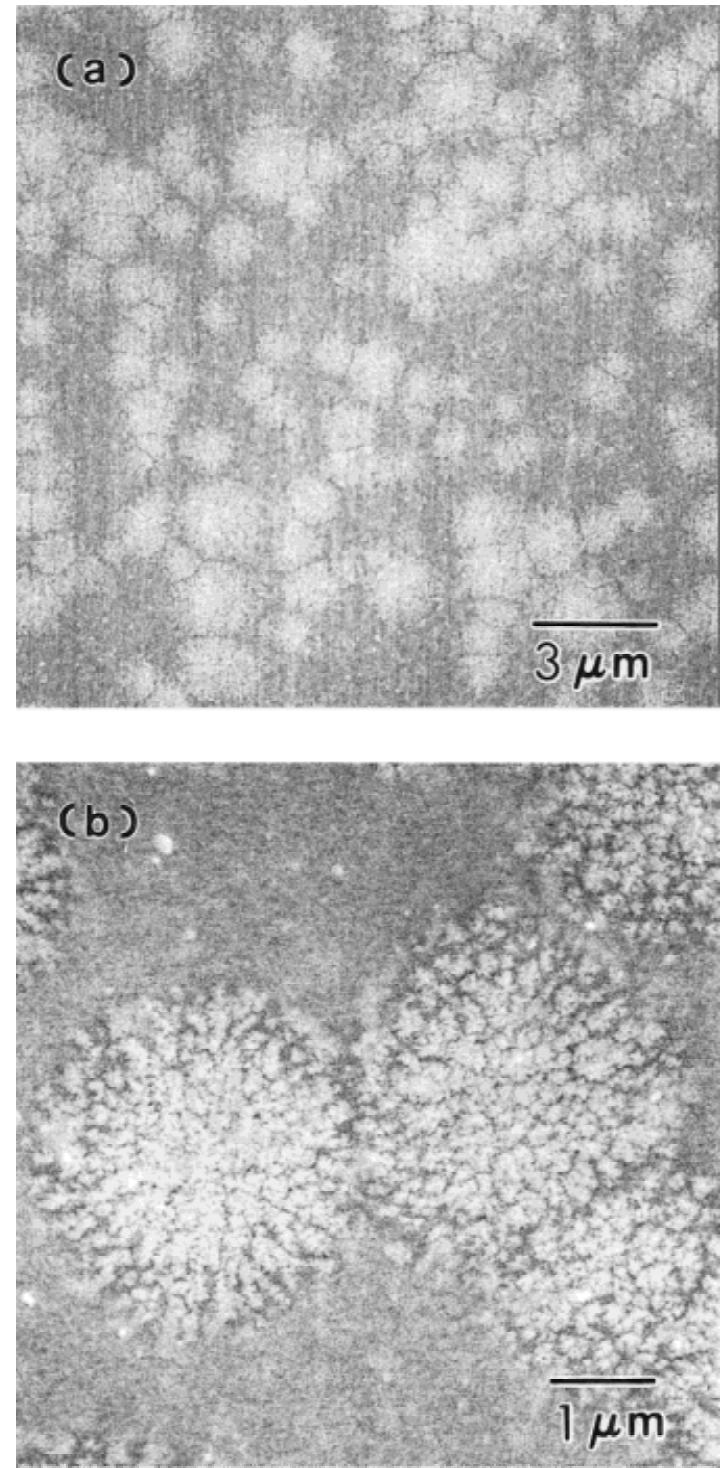

Fig. 10. SEM micrographs of MOD film first pyrolyzed at $400^{\circ} \mathrm{C}$ for $0.5 \mathrm{~h}$ and then heated at $650^{\circ} \mathrm{C}$ for $0.5 \mathrm{~h}$ with a heating rate of $1^{\circ} \mathrm{C} / \mathrm{min}$; (a) low and (b) high magnification.

order of $30 \mathrm{~nm}$, but the orientation of different rosettes was random. While this point has not been verified in the present study, our XRD did confirm that the texture was essentially random.

The above observation again suggests that microstructure and texture development in both MOD and sol-gel films follows a similar path. The slow heating rate used is believed to cause a severe $\mathrm{PbO}$ loss and a nearly complete destruction of first crystallized $\mathrm{PbO}$ phase. Hence, nucleation of perovskite lacks a preferred orientation. Apparently, the number of perovskite nuclei is so low that the formation of perovskite is highly nucleation controlled. (The observed spherulite morphology with a center primary nucleus for each spherulite is quite common in amorphous materials and high polymers where the number of nuclei is likewise limited.) In addition, perovskite crystallization cannot proceed to completion in some of the interspherulite region where severe depletion of $\mathrm{PbO}$ has prevented perovskite formation in both MOD and sol-gel films. Lastly, the different appearance of spherulite morphology in the two films may be a consequence of different diffusion profile. In the case of MOD films, some short-range cation redistribution during perovskite/pyrochlore transformation is possibly allowed considering the unassociated nature of cations in MOD precursors. The local concentration gradient 

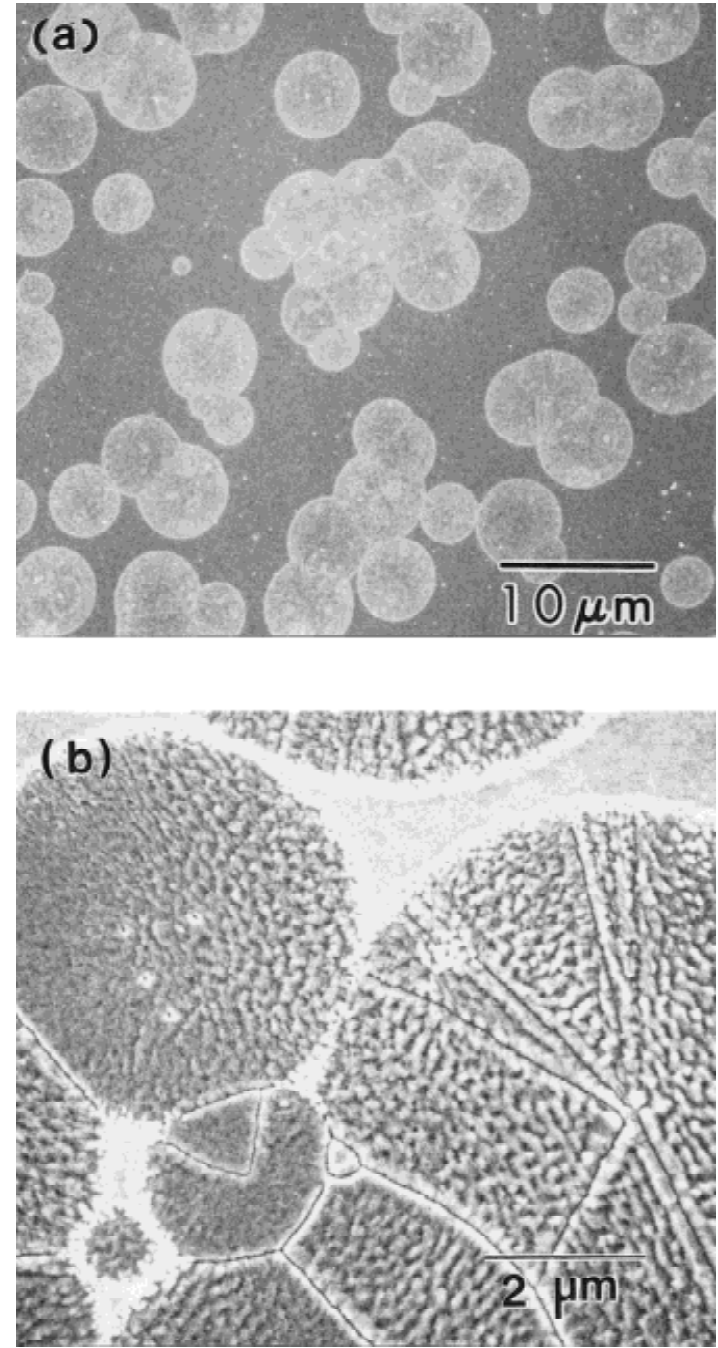

Fig. 11. SEM micrographs of sol-gel film first pyrolyzed at $400^{\circ} \mathrm{C}$ for $0.5 \mathrm{~h}$ and then heated at $650^{\circ} \mathrm{C}$ for $0.5 \mathrm{~h}$ with a heating rate of $1^{\circ} \mathrm{C} / \mathrm{min}$ at (a) low and (b) high magnification.

thus favors the formation of an undulated interface (much like dendritic growth in the extreme), giving rise to a fuzzy appearance of the boundary. On the other hand, sol-gel precursors have definite polymeric structures whose ligands remain even at relatively high temperatures. This could severely restrict the mobility of cations with respect to concentration redistribution. As a result, a sharp boundary is always maintained during growth.

\section{(6) Electrical Properties}

The electrical properties of films are usually a direct consequence of the microstructure. The properties of both MOD and sol-gel $\mathrm{Pb}_{1.1}\left(\mathrm{Zr}_{0.52} \mathrm{Ti}_{0.48}\right) \mathrm{O}_{3}$ films for both (111) and (100) orientations are summarized in Table I. Both types of films were prepared following the same seeding procedures and annealing conditions (directly heated at $700^{\circ} \mathrm{C}$ for $0.5 \mathrm{~h}$ ). The properties were measured at room temperature at a frequency of $1 \mathrm{kHz}$. A more detailed discussion of the relation between

Table I. Electrical Properties of Oriented PZT Thin Films

\begin{tabular}{lccccccc}
\hline & \multicolumn{3}{c}{$\begin{array}{c}\text { Process MOD } \\
(0.52 \mu \mathrm{m})\end{array}$} & & \multicolumn{3}{c}{$\begin{array}{c}\text { Process sol-gel } \\
(0.32 \mu \mathrm{m})\end{array}$} \\
\cline { 2 - 4 } \cline { 6 - 8 } $52 \mathrm{Zr} / 48 \mathrm{Ti}$ & $\operatorname{Pr}^{\dagger}$ & $\mathrm{Ec}^{*}$ & $\epsilon^{\S}$ & & $\operatorname{Pr}$ & $\mathrm{Ec}$ & $\epsilon$ \\
\hline$(100)$ & 21.4 & 54 & 855 & & 18.9 & 59 & 637 \\
$(111)$ & 23.9 & 63 & 912 & & 27.3 & 71 & 937 \\
\hline
\end{tabular}

${ }^{\dagger} \operatorname{Pr}\left(\mu \mathrm{C} / \mathrm{cm}^{2}\right)$ : remanent polarization. ${ }^{*} \mathrm{Ec}(\mathrm{kV} / \mathrm{cm})$ : coercive field. ${ }^{\S} \epsilon$ : dielectric constant. electrical properties and various parameters including texture, composition and microstructure is given in Ref. 21 , to which the reader is referred.

\section{Conclusions}

(1) The texture selection of PZT films can be controlled through similar heating schedules independent of precursor systems.

(2) The texture selection is sensitive to the film thickness especially when sol-gel precursors and oxidizing atmosphere are used. This is related to the lower carbon content of sol-gel precursors.

(3) Microstructure development and perovskite content are strongly dependent on the heat treatment, especially on the heating rate. Fast heating rate forms a dense fine-grained microstructure with (111) orientation. Intermediate-temperature pyrolysis followed by a fast heating rate forms clustered or island structures of submicrometer grains with (100) orientation. Intermediate-temperature pyrolysis followed by a very slow heating rate forms larger spherical rosettes with random orientations.

(4) The amount of perovskite decreases in the above order and is especially low in sol-gel films undergoing slower heating. This is because of the higher crystallization temperature in the sol-gel films, which in turn suffer more PbO loss.

\section{References}

${ }^{1}$ K. D. Budd, S. K. Dev, and D. A. Payne, "'Sol-Gel Processing of $\mathrm{PbTiO}_{3}$ $\mathrm{PbZrO}_{3}$, PZT and PLZT Thin films,' Br. Ceram. Proc. 36, 107-21 (1985).

${ }^{2}$ R. W. Schwartz, B. C. Bunker, D. B. Dimos, R. A. Assink, B. A. Tuttle, D. R. Tallant, and I. A. Weinstock, "Solution Chemistry Effects in $\mathrm{Pb}(\mathrm{Zr}, \mathrm{Ti}) \mathrm{O}_{3}$ Thin Film Processing,', Integr. Ferroelectr. 2, 243-54 (1992).

${ }^{3}$ J. Fukushima, K. Kodaira, and T. Matsushita, "Preparation of Ferroelectric PZT Films by Thermal Decomposition of Organometallic Compounds," $J$. Mater. Sci., 19, 595-98 (1984)

${ }^{4}$ R. W. Vest, "Metallo-organic Decomposition (MOD) Processing of Ferroelectric and Electro-optical Films: A Review,' Ferroelectrics, 102, 53-68 (1990)

${ }^{5}$ R. W. Vest, "Electronic Films from Metallo-organic Precursors"; pp. 303 41 in Ceramic Films and Coating. Edited by J. B. Wachtman and R. A. Haber. Noyes Publications, Park Ridge, NJ, 1993.

${ }^{6}$ K. C. Chen and J. D. Mackenzie, "Crystallization Kinetics of Metalloorganic Derived PZT Thin Films,'” Mater. Res. Soc. Symp. Proc., 180, 663-68 (1990).

${ }^{7}$ R. A. Lipeles, D. J. Coleman, and M. S. Leung, "Effects of Hydrolysis on Metallo-organic solution Deposition on PZT Films,' Mater. Res. Soc. Symp. Proc., 73, 665-70 (1986).

${ }^{8}$ G. H. Haertling, "PZT Thin Films Prepared from Acetate Precursors,' Ferroelectrics, 116, 51-63 (1991).

${ }^{9}$ G. A. C. M. Spierings, J. B. A. van Zon, M. Klee, and P. K. Larsen, "Influence of Platinum-Based Electrodes on the Microstructure of Sol-Gel and MOD Prepared Lead Zirconate Titanate Films,'" Integr. Ferroelectr., 3 [3] 280-89 (1993).

${ }^{10} \mathrm{M}$. Klee, R. Eusemann, R. Waser, and W. Brand "Processing and Electrical Properties of $\mathrm{Pb}\left(\mathrm{Zr}_{x} \mathrm{Ti}_{1-x}\right) \mathrm{O}_{3}(x=0.2-0.75)$ Films: Comparison of Metallo-organic Decomposition and Sol-Gel Processes,', J. Appl. Phys., 72 [4] 1566-76 (1992)

${ }^{11}$ M. Klee, P. Schnabel, W. Brand, and R. Mauczok, "Ferroelectric Layers Made by Thermal Decomposition of Organometallic Compounds'; pp. 685-88 in Proceedings of the 7th IEEE International Symposium on Applications of Ferroelectrics. Edited by S. B. Krupanidhi and S. K. Kurtz. Institute of Electrical and Electronics Engineering, Piscataway, NJ, 1990.

${ }^{12}$ T. Tani, Z. Xu, and D. A. Payne, "Preferred Orientation for Sol-Gel Derived PLZT Thin Layers"; pp. 269-74 in Materials Research Society Symposium Proceedings, Vol. 310, Ferroelectric Thin Films III. Materials Research Society, Pittsburgh, PA, 1993.

${ }^{13}$ S. Y. Chen and I-W. Chen, "Temperature-Time-Texture transition of $\mathrm{Pb}(\mathrm{Zr}, \mathrm{Ti}) \mathrm{O}_{3}$ Thin Films: I, The Role of Pb-Rich Intermediate Phases, ' J. Am. Ceram. Soc., 77 [9] 2332-36 (1994).

${ }^{14} \mathrm{~S}$. Y. Chen and I-W. Chen, "Temperature-Time-Texture Transition of $\mathrm{Pb}(\mathrm{Zr}, \mathrm{Ti}) \mathrm{O}_{3}$ Thin Films: II, Heat Treatment and Compositional Effects,' J. Am Cream. Soc., 77 [9] 2337-44 (1994).

${ }^{15}$ S. Hirano, T. Yugo, K. Kikuta, Y. Araki, M. Saitoh, and S. Ogasahara, "Synthesis of Highly Oriented Lead Zirconate-Lead Titanate Film Using Metallo-organics,' J. Am. Ceram. Soc., 75 [10] 2785-89 (1992).

${ }^{16}$ G. A. C. M. Spierings, M. J. E. Ulenaers, G. L. M. Kampschoer, H. A. M. van Hal, and P. K. Larsen, "Preparation and Ferroelectric Properties of $\mathrm{PbZr}_{0.53} \mathrm{Ti}_{0.47} \mathrm{O}_{3}$ Thin Films by Spin Coating and Metalorganic Decomposition," J. Appl. Phys., 70 [4] 2290-98 (1991).

${ }^{17}$ K. G. Brooks, I. M. Reaney, R. Klissurska, Y. Huang, L. Bursill, and N. Setter, "Orientation of Rapid Thermally Annealed Lead Zirconate Titanate Thin Films on (111) Pt Substractes," J. Mater. Res., 7 [10] 2540-53 (1994). 
${ }^{18}$ Y. Liu and P. P. Phule, "Nucleation- or Growth-Controlled Orientation Development in Chemically Derived Ferroelectric Lead Zirconate Titanate $\left(\mathrm{Pb}\left(\mathrm{Zr}_{x} \mathrm{Ti}_{1-x}\right) \mathrm{O}_{3}, x=0.4\right)$ Thin Films," J. Am. Ceram. Soc., 79 [2] 495-98 (1996).

${ }^{19}$ I. M. Reaney, K. G. Brooks, R. Klissurska, C. Pawlaczyk, and N. Setter, "Use of Transmission Electron Microscopy for the Characterization of Rapid Thermally Annealed, Solution-Gel, Lead Zirconate Titanate Films,' J. Am. Ceram. Soc., 77 [5] 1209-16 (1994).

${ }^{20}$ K. Brooks, R. Klissurska, P. Moeckli, and N. Setter, "Investigation of $\mathrm{Pb}\left(\mathrm{Zr}_{0.7} \mathrm{Ti}_{0.3}\right) \mathrm{O}_{3}$ Thin Films of Different Textures on Ti/Pt Electrodes,' Microelectroni. Eng., 29, 293-96 (1995).

${ }^{21} \mathrm{~S}$. Y. Chen and I-W. Chen, "Comparative Study of Electrical Properties in [100] and [111]-Oriented PZT Films,', Jpn. J. Appl. Phys., Part 1, 36 [7A] 4451-58 (1997).

${ }^{22}$ C. D. E. Lakeman, J-F. Campion, and D. A. Payne "Factors Affecting the Sol-Gel Processing of PZT Thin Layers,' Ferroelectr. Films, 25, 413-39 (1992)

${ }^{23}$ K. Aoki, Y. Fukuda, and A. Nishimura, "Preparation of (100) Oriented Lead Zirconate Titanate films by Sol-Gel Technique,' Jpn. J. Appl. Phys., Part 1, 32 [9B] 4147-49 (1993).
${ }^{24}$ R. A. Lipeles, N. A. Ives, and M. S. Leung, "Sol-Gel Processing of Lead Zirconate Titanate films"; pp. 320-26 Ultrastructure Processing of Ceramics, Glasses and Composites. Edited by L. L. Hench and D. R. Ulrich. Wiley, New York, 1986.

${ }^{25}$ C. K. Kwok, S. B. Desu, and D. P. Vijay, "'Modified Sol-Gel Process for Preparation of Lead Zirconate Titanate Thin Films,' Ferroelectr. Lett., 16, 143-56 (1993)

${ }^{26}$ B. A. Tuttle, T. J. Headley, B. C. Bunker, R. W. Schwartz, T. J. Zender, C. L. Hernandez, D. C. Goodnow, R. J. Tissot, and J. Michael, "Microstructural Evolution of $\mathrm{Pb}(\mathrm{Zr}, \mathrm{Ti}) \mathrm{O}_{3}$ Thin Films Prepared by Hybrid Metal-organic Decomposition," J. Mater. Res., 7 [7] 1876-82 (1992).

${ }^{27}$ S. A. Myers and L. N. Chapin, "Microstructural Characterization of Ferroelectric Thin Films for Nonvolatile Memory Applications,', Mater. Res. Soc. Symp. Proc., 200, 231-36 (1990).

${ }^{28}$ H. D. Keith and F. J. Padden, Jr., "Spherulitic Crystallization from the Melt. I. Fractionation and Impurity Segregation and Their Influence on Crystalline Morphology,"' J. Appl. Phys., 15 [4] 1270-85 (1964).

${ }^{29}$ A. H. Carim, B. A. Tuttle, D. H. Doughty, and S. L. Martinez, "Microstructure of Solution-Processed Lead Zirconate Titanate (PZT) Thin Films, " $J$. Am. Ceram. Soc., 74 [6] 1455-58 (1991). 